\title{
$\mathrm{Bt}$ 양배추가 복숭아혹진딧물의 발육과 기주선택에 미치는 영향
}

남기정 · 김영중 · 문두범 · 남경희 · 백인순 · 박정호 · 정순천 · 한지학 ${ }^{1}$ 김창기 ${ }^{*}$

한국생명공학연구원 바이오평가센터, ${ }^{1}$ (주)농우바이오 R\&D본부

\section{Effects of Bt Cabbage (Brassica oleracea) on the Host Preference and Performance of the Green Peach Aphid, Myzus persicaeSulzer (Hemiptera: Aphididae)}

\author{
Ki Jung Nam, Young-Joong Kim, Doo-Bum Moon, Kyong-Hee Nam, In Soon Pack, Jung-Ho Park, Soon-Chun Jeong,
} Chee Hark Harn ${ }^{1}$ and Chang-Gi Kim*

Bio-Evaluation Center, KRIBB, Cheongwon 363-883, Republic of Korea

${ }^{1}$ R\&D Headquarter, Nongwoo Bio Co., Yeoju 469-885, Republic of Korea

\begin{abstract}
Transgenic crops that produce insecticidal toxins have a great potential for controlling target pest insects, but there is a growing concern about unintended influences on non-target species. In the present study, the preferences and performance of non-target green peach aphid, Myzus persicae (Sulzer), on transgenic cabbages (Brassica oleracea) that produce Bt toxin (Cry1Ac1) and untransformed control plants were investigated as a part of risk assessment. In a free-choice situation, the number of nymphs larviposited by 10 winged adults over 3 days was $21.9 \pm 1.8$ and $22.5 \pm 2.2$ on transgenic and the control plants, respectively, indicating that the aphids did not discriminate between the two types of plants. In a performance assay, the development time (D) and intrinsic rate of increase ( $\left.\mathrm{r}_{\mathrm{m}}\right)$ of wingless aphids reared on transgenic and control plants were also similar (D, 5.8 \pm 0.2 and $5.9 \pm 0.1$ (days) and $\mathrm{r}_{\mathrm{m}}, 0.7 \pm 0.1$ and $0.8 \pm 0.1$, for transgenic and control plants, respectively). These results suggest that $M$. persicae is not significantly affected by transgenic Bt cabbage.
\end{abstract}

Key words: Environmental risk assessment, Bt cabbage, Host preference, Myzus persicae, Transgenic crop

\begin{abstract}
초 록: 해충저항성 유전자변형 작물은 대상 해충에 대한 방제 효과를 증진시킬 수 있는 효과적인 수단이 될 수 있지만, 생태계 내의 다른 비표적 생 물에 부정적인 영향을 줄 가능성 또한 있기 때문에 상업적인 재배에 앞서 이에 대한 충분한 연구가 이루어져야 한다. 본 연구에서는 배추좀나방 내성 유전자변형 $\mathrm{Bt}$ (Cry1Ac1)양배추가 비표적 곤충인 복숭아혹진딧물에 미치는 영향을 알아보기 위한 기초적인 실험으로서 기주선택실험 및 성장실험을 실시하였다. 기주선택실험에서, 두 개체씩의 $\mathrm{Bt}$ 양배추와 모본 양배추에 각각 10마리의 유시 성충(alate virginoparae)을 접종하고,

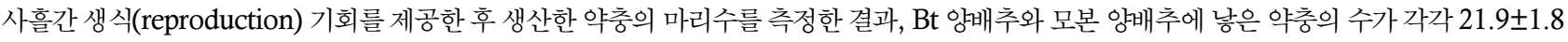
와 22.5 \pm 2.2 로 비슷하였다. 성장실험에서, 갓 태어난 무시 약충(apterous virginoparae)을 Bt 양배추 및 모본 양배추를 기주로 하여 키웠을 때, 성충이 될 때까지 걸린 시간은 $\mathrm{Bt}$ 양배추와 모본 양배추에서 각각 $5.8 \pm 0.2,5.9 \pm 0.1$ 일(day)로 통계적으로 유의한 차이가 없었고, 개체군 생장률 $\left(\mathrm{r}_{\mathrm{m}}\right)$ 또한 $0.7 \pm 0.1,0.8 \pm 0.1$ 로 유사하였다. 이상의 결과들로 볼때 $\mathrm{Bt}$ 양배추가 복숭아혹진딧물에 미치는 영향이 없거나 미미함을 알 수 있으나, 다양한 관점에서의 보완 연구가 더 필요하다.
\end{abstract}

검색어: 환경위해성평가, $\mathrm{Bt}$ 양배추, 기주선택, 복숭아혹진딧물, 유전자변형 작물

토양세균 Bacillus thuringiensis가 영양세포에 내생포자를 생성할 때 만들어내는 단백질(내독소; Cry toxin)이 나비목, 파

*Comesponding author: cgkim@kribb.re.kr

Received December 30 2013; Revised February 252014

Accepted March 202014
리목 및 딱정벌레류의 특정 곤충에 선택적으로 살충성을 나타 냄이 알려진 이후, 이 단백질을 생물학적 방제에 이용하기 위한 연구가 꾸준히 진행되어왔다(Park, 2011). 특히, B. thuringiensis 에서 유래한 $c r y$ 유전자를 식물체에 삽입함으로써 살충성 내 독소가 식물체 내에서 직접 발현되도록 개발된 유전자변형 
(Genetically modified, GM) Bt 면화, 옥수수, 콩 등이 상업적으 로 널리 이용되고 있다(Romeis et al., 2006; Kumar et al., 2008). 그러나 식물체의 유전자변형 과정에서 생기는 의도적 또는 비 의도적 변화가 생태계 내에 야기할 수 있는 여러 영향들에 대한 우려가 꾸준히 증가하여, 이제 세계 여러 나라에서 $\mathrm{GM}$ 식물을 상업화하기 위한 전제조건으로서 $\mathrm{GM}$ 식물이 표적 및 비표적 생물에 미치는 영향을 측정하는 환경위해성 평가를 강제하고 있다(Kuiper et al., 2001; Hilbeck et al., 2011).

국내에서는 최근까지 $\mathrm{Bt}$ 내독소 발현 유전자 중 $c r y 1 A c 1$ 유 전자가 삽입된 벼와 배추, 그리고 $c r y 1 A$ 가 삽입된 옥수수를 대 상으로 연구들이 수행되었는데, 대체적으로 $\mathrm{Bt}$ 내독소가 비표 적 생물에 미치는 영향이 크지 않음이 보고되었다. $\mathrm{Bt}$ 벼의 경 우, 표적 곤충인 혹명나방(Cnaphalocrocis medinalis), 벼애나 방(Naranga aenescens), 그리고 비표적 절지동물의 경우, 초식 곤충인 벼멸구(Nilaparvata lugens), 벼메뚜기(Oxya japonica), 먹노린재(Scotinophara lurida), 꽃가루섭식곤충인 꼬마남생 이무당벌레(Propylea japonica), 그리고 포식자인 황산적늑대 거미(Pirata subpiraticus), 턱거미(Pachygnatha clercki)에 관 한 영향이 연구되었고, 수생생물로는 물벼룩(Daphnia magna), 미꾸리(Misgurnus anguillicaudatus), 잉어(Cyprinus carpio)에 대한 독성실험 결과도 보고되었으며, 토양미생물에 미치는 영 향도 연구되었다(Oh et al., 2011a, b; Lee, 2012; Sohn et al., 2012). $\mathrm{Bt}$ 배추의 경우 비표적 해충인 도둑나방(Mamestra brassicae) 과 도둑나방의 천적인 큰밤고치벌(Microplitis mediator)에 미 치는 영향, 그리고 배추 꽃가루가 누에나방(Bombyx mori)에 미 치는 영향도 연구되었다(Kim et al., 2008a, b). Bt 옥수수의 경 우는 국내에서 개발된 GM식물은 아직 없으나 수입된 GM 식 물이 통제에서 벗어나 자연계에 유출될 것을 예상한 실험이 진 행되었는데, 갈색 거저리(Tenebrio molitor)와 기장테두리진딧 물(Rhopalosiphum padi)을 비표적 곤충으로 실험에 사용하였 다(Kim et al., 2012a, b).

본 연구는 (주)농우바이오에서 개발중인 배추좀나방 내성 $\mathrm{GM} \mathrm{Bt}$ 양배추(Brassicae oleracea)의 환경위해성 평가의 일환 으로서, $\mathrm{Bt}$ 양배추가 대표적인 비표적 곤충인 복숭아혹진딧물 (Myzus persicae Sulzer)의 기주식물 선택 및 성장에 미치는 영 향을 실내실험을 통해 알아보았다. 복숭아혹진딧물은 40 과 수 백종의 식물을 기주로 사용하는 우리나라 중요농업해충이므로 $\mathrm{Bt}$ 내독소에 미치는 영향 연구의 대상으로 적합하다. 본 연구에 서는 기주선택 후 다음 세대(약충)의 진화적 관점의 성공율 (fitness)을 기주선택 후의 산란성공률 및 발육속도로 측정하였 는데, 이는 비표적 생물이 유전자변형 식물을 기주로 선택함으 로써 얻는 이익 및 손해를 파악하는 방법으로 적절하여 유사연
구에 널리 이용되어 왔다(Ramirez-Romero et al., 2008; Lawo et al., 2009; Digilio et al., 2012).

\section{재료 및 방법}

본 실험에 사용한 $\mathrm{Bt}$ 양배추(이벤트 $\mathrm{C} 30$ )는 (주)농우바이오 생명공학연구소에서 모본 양배추(AD126)에 $\mathrm{Bt}(\mathrm{Cry} 1 \mathrm{Ac})$ 독 소를 발현시키는 유전자 $c r y 1 A c l$ 을 삽입하여 개발한 것이다. 잎에서의 독소 발현량은 1.3 1.4 $\mu \mathrm{g} / \mathrm{g} \mathrm{F.W}$. 이며, 잎을 배추좀 나방(Plutellaxylostella) 유충에 제공하였을 때 양배추 잎 섭식 시작 후 4 일 안에 죽는 것이 관찰되었다. 실험을 위하여 $\mathrm{C} 30$ 양 배추와 모본 $\mathrm{AD} 126$ 의 종자를 (주)농우바이오 온실에서 파종 한 후 본 잎이 2 3장 나왔을 때 PCR을 이용하여 유전자가 삽입 된 개체를 선별하였다. 선별된 유식물들은 한국생명공학연구 원 바이오평가센터(충북 청원군 오창읍 소재)의 온실로 옮긴 후, 각각의 개체를 화분(직경 $11.5 \mathrm{~cm}$ )에 상토(부농원예용상토, (주)부농)를 이용하여 이식한 뒤 실험 시까지 유지 $\left(17 \sim 35^{\circ} \mathrm{C}\right.$, 자연광)하였다. 실험은 개체들의 잎의 수가 8-10개가 되었을 때 실시하였다.

복숭아혹진딧물(M. persicae Sulzer)은 농촌진흥청 국립원 예특작과학원에서 분양 받은 후, 배추(Brassica rapa var. glabra; 서울배추, (주)신젠타종묘)를 기주식물로 하여 실험 시까지 항 온항습실 $\left(25 \pm 1^{\circ} \mathrm{C}\right.$, 습도 $50 \pm 5 \%$, 광주기 $\left.16: 8 \mathrm{~h}(\mathrm{~L}: \mathrm{D})\right)$ 에서 누대 사육하였다. 기주선택실험에 사용할 유시 성충(alate virginoparae) 을 얻기 위하여, 두 개의 아크릴 케이지(가로 $\times$ 세로 $\times$ 높이, $55 \times$ $22 \times 30 \mathrm{~cm}$ )안에 배추 유식물을 각 3 개체씩 넣고 각 개체에 각각 10 마리의 무시 성충(apterous virginoparae) 진딧물을 붓으로 옮 겨놓은 후 여러 세대 동안 번식하도록 두어, 자연스럽게 유시충 을 만들어내도록 유도하였다. 실험은 유시충 진딧물이 성충이 된 후 3-4일이 지나 생식(reproduction)이 가능한 개체들을 이 용하였다.

기주선택실험은 아크릴 케이지 $(30 \times 30 \times 35 \mathrm{~cm})$ 안에 C30, $\mathrm{AD} 126$ 양배추 각 두 개체씩 (케이지 모서리 네 부분에 대각선 으로 같은 계통의 식물을 배치) 위치시킨 후, 진딧물 유시 성충 10 마리를 넣고 72시간 후 각 식물체에 낳은 약충의 수를 세었 으며 $(\mathrm{n}=13)$, 이를 기주선택의 지표로 사용하였다(Powell et al., 2006). Bt 양배추와 모본 양배추를 기주로 하였을 때의 진 딧물 약충의 발육기간(development time; D)과 개체군 생장률 (an intrinsic rate of increase; $\mathrm{r}_{\mathrm{m}}$ )을 측정하기 위하여, AD126, $\mathrm{C} 30$ 각각의 개체당 세 마리의 무시 성충을 접종시킨 후, 24시 간 뒤 3 마리의 약충만 남기고 성충진딧물과 그 외 나머지 약충 들을 모두 제거하였다. 남겨놓은 세 마리의 약충은 3 일 뒤 안정 
기에 접어들었다고 판단되었을 때 다시 한 마리만 남기고 제거 하였으며, 남은 한 마리는 성충이 될 때까지 모니터링하였다. 또 한, 개체군 생장률 $\left(\mathrm{r}_{\mathrm{m}}\right)$ 은 성충이 된 후 번식을 시작할 때까지 걸 린 기간만큼의 기간 동안 지속적으로 성충을 더 모니터링하여 생 산한 약충의 수를 세어 구하였다 $(\mathrm{n}=15)$. 발육기간(development time)은 아래와 같이 정의하였으며, 개체군 생장률 $\left(\mathrm{r}_{\mathrm{m}}\right)$ 은 아래 의 식을 이용하여 계산하였다(Wyatt and White, 1977).

Development time (D) = time taken from birth to final moult $\mathrm{r}_{\mathrm{m}}$ (an intrinsic rate of increase $)=0.74 \times \ln \left(\mathrm{M}_{\mathrm{d}} / \mathrm{T}\right)$

$\mathrm{M}_{\mathrm{d}}$ : reproductive output per female during period equal to $\mathrm{T}$

$\mathrm{T}$ : the time from birth to onset of reproduction

0.74: correction factor

모든 실험은 $25 \pm 1^{\circ} \mathrm{C}$, 습도 $50 \pm 5 \%$, 광주기 $16: 8 \mathrm{~h}(\mathrm{~L}: \mathrm{D})$ 의 항온항습실에서 실시하였다.

데이터의 분석은, 기주선택실험 시 진딧물이 생산한 약충의 수를 비교하기 위해서 가산자료(count data)를 분석하는데 적 합한 모델인 generalized linear model (GLM; quasi-poisson; 자료가 과대산포하였기 때문에 quasi-poisson을 사용)을 이용 하였고, 발육기간(D)을 비교하기 위하여는 Wilcoxon의 rank sum test, 그리고 개체군 생장률 $\mathrm{r}_{\mathrm{m}}$ 값의 비교는 t-test 를 이용하 였다. 발육기간 데이터는 t-test를 하기 위한 기본가정인 정규분 포와 유사한 분산도를 만족하지 못하였기 때문에 비모수 방법 인 Wilcoxon 법을 사용하였다. 모든 분석은 R 패키지를 이용하 였다(R development core team, 2012).

\section{결과 및 고찰}

복숭아혹진딧물 유시 성충 10 마리를 $\mathrm{C} 30, \mathrm{AD} 126$ 양배추에 노출시켜 자유롭게 생식하도록 두었을 때 72시간동안 낳은 약 충의 수는 $\mathrm{C} 30, \mathrm{AD} 126$ 양배추에서 각각 $22.5( \pm 2.2), 21.9$ $( \pm 1.8)$ 마리 $( \pm$ S.e)로 통계적으로 유의한 차이가 없었다(GLM quasi-poisson, $\mathrm{t}=0.24, \mathrm{p}=0.81$ ) (Fig. 1). 또한, $\mathrm{C} 30, \mathrm{AD} 126$ 양 배추에서 복숭아혹진딧물 약충의 발육기간(D)은 각각 $5.93 \pm 0.12$, $5.80 \pm 0.17$ 일(days), 그리고 개체군 생장률 $\mathrm{r}_{\mathrm{m}}$ 은 각각 $0.84 \pm 0.07$, $0.67 \pm 0.13$ 로 두 양배추간 차이가 없었다(development time: $\mathrm{W}$ $=127, \mathrm{p}=0.48 ; \mathrm{r}_{\mathrm{m}}$ : t-test $\mathrm{t}=1.15, \mathrm{p}=0.26$ ) (Fig. 2). 본 실험결 과로 볼 때, 복숭아혹진딧물 유시 성충이 생식(reproduction)을 위한 기주선택 시 AD126과 C30 양배추를 구별하지 않았으며, 또한 $\mathrm{C} 30, \mathrm{AD} 126$ 양배추가 복숭아혹진딧물 기주로서의 질 (quality) 측면에서 큰 차이가 없는 것으로 사료된다.

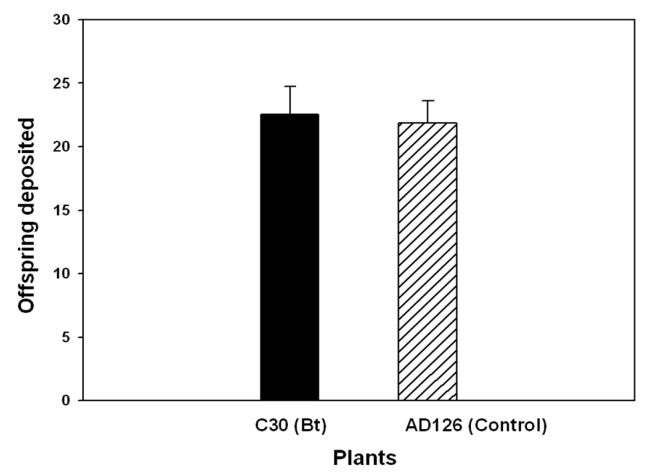

Fig. 1. Number of offspring produced by 10 winged virginoparae of Myzus persicae Sulzer on C30 (Bt) and AD126 (non-Bt control) cabbage plants over $72 \mathrm{~h}(\mathrm{n}=13)$. There was no significant difference between C30 and AD126 plants at $P<0.05$. Data are mean +1 standard error.

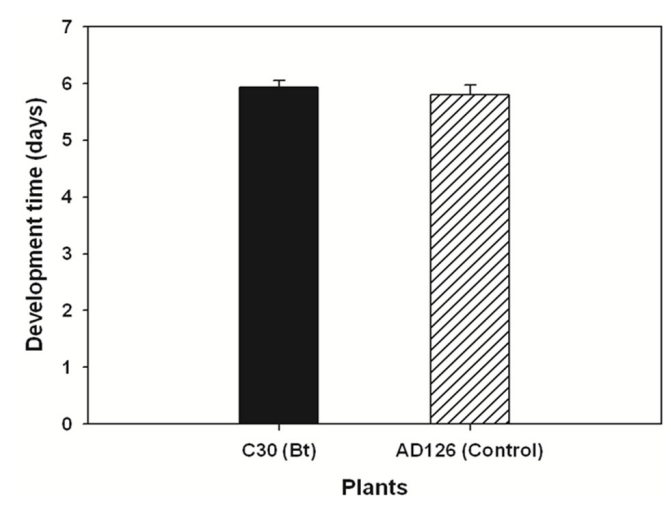

(a) Development time (D)

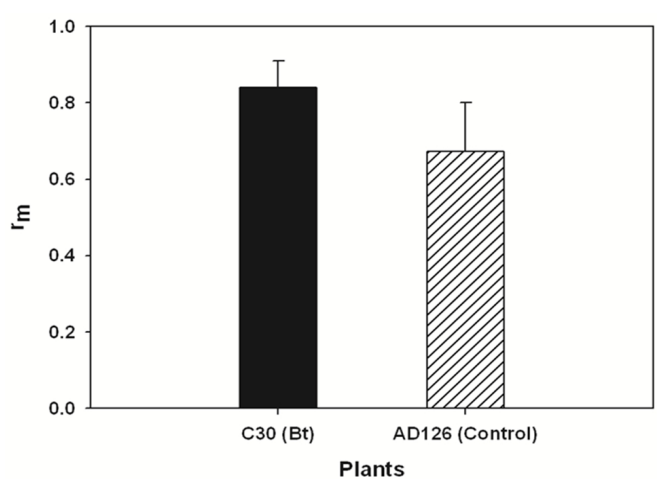

(b) Intrinsic rate of increase $\left(\mathrm{r}_{\mathrm{m}}\right)$

Fig. 2. (a) Development time (D) and (b) intrinsic rate of increase $\left(r_{m}\right)$ of wingless virginopara nymphs of Myzus persicae Sulzer fed on C30 (Bt) and AD126 (non-Bt control) cabbage plants ( $n=15$ for each group). There was no significant difference in either $D$ or $r_{m}$ between $\mathrm{C} 30$ and $\mathrm{AD} 126$ plants at $\mathrm{P}<0.05$. Data are mean +1 standard error.

최근까지 $\mathrm{Bt}$ 작물이 진딧물에 미치는 영향에 관한 연구는, 주로 $\mathrm{Bt}$ 면화와 목화진딧물(Aphis gossypii), 그리고 Bt 옥수수 와 기장테두리진딧물(R.padi) 또는 보리수염진딧물(Sitobion 
avenae)을 실험대상으로 진행되었다. 연구결과들은 대체적으 로 $\mathrm{Bt}$ 작물이 진딧물의 발육기간과 생식력(fecundity) 또는 발 육에 영향을 주지 않음을 보고하고 있으나(Lozzia et al., 1998; Dutton et al., 2002; Liu et al., 2005; Ramirez-Romero et al., 2008; Lawo et al., 2009; Digilio et al., 2012), 진딧물의 생식력 과 발육에 부정적인 영향(Zhang et al., 2008), 또는 반대로 긍정 적인 영향(Lumbierres et al., 2004)을 나타냄도 보고하고 있어 일반화를 위해서는 더 많은 연구가 필요하다. 또한, 미국, 중국 등 일부 국가에서 $\mathrm{Bt}$ 작물의 대규모 상업적 재배가 가능해진 이 후, 실험실에서 진딧물 개체를 대상으로 얻은 실험 결과로부터 개체군 수준에서의 변화를 유추해내는 방법이 아닌, 실지 야외 포장에서 $\mathrm{Bt}$ 작물에 서식하는 진딧물의 개체군 동태를 직접 모 니터링 하는 방법으로의 연구도 진행되었다. 이러한 개체군 수 준의 연구의 결과들은 $\mathrm{Bt}$ 작물이 진딧물의 개체군 동태에 어느 정도 영향을 미칠 수 있음을 시사하지만, 영향의 방향성(positive or negative) 측면에서는 $\mathrm{Bt}$ 작물에서 진딧물의 밀도가 더 낮거 나(Wu and Guo, 2003; Fernandes et al., 2012), 또는 더 높은 등 (Pons et al., 2005), 일관되지 않음을 알 수 있다. 이는 더 많은 연구가 필요함을 의미하기도 하지만, $\mathrm{Bt}$ 작물이 진딧물에 미칠 수 있는 영향의 방향 및 크기가 $\mathrm{Bt}$ 내독소를 포함한, 식물체와 연관된 다양한 요소들의 상호작용에 의해 결정될 수 있음 (context or case dependent)을 의미하는 것으로 생각된다.

$\mathrm{Bt}$ 작물이 진딧물에 영향을 미치는가에 관한 연구와 더불어 $\mathrm{Bt}$ 내독소가 진딧물에 의해 체내로 흡수되어 저장되는가에 관 하여도 그간 논란이 되어 왔다(Raps et al., 2001; Burgio et al., 2007, 2011). 이는 진딧물이 직접적으로 내독소에 의해 영향을 받는가에 관한 문제뿐만 아니라 진딧물을 통하여 내독소가 생 태계 내 먹이사슬의 상위단계로 전달되는가에 관한 문제로서 연구자들의 주요 관심의 대상이기도 하다. 그간의 연구결과들 은 대체로 진딧물 체내에 미량 또는 측정한계 이하의 소량의 내 독소가 존재함을 보고하여, 진딧물의 체내에 내독소가 흡수 저 장되지 않고, 결과적으로 진딧물을 포식하는 포식자에게 내독 소가 이동, 축적되지 않는다는 쪽으로 의견이 모아지고 있는 듯 하다(Romeis and Meissle, 2011). Bt 내독소가 식물체 내 체관 에 거의 존재하지 않음이 보고되었고, 진딧물의 체관을 통한 섭 식행동과 연관 지어 진딧물이 내독소에 거의 노출되지 않을 것 이라는 추론을 가능하게 하였다(Raps et al., 2001; Burgio et al., 2007). 그러나 연구의 대부분이 내독소 중 Cry1 Ab, Cry1Ac 또는 Cry3를 대상으로 하였으므로 다른 내독소를 발현시키는 $\mathrm{GM}$ 식물에 대해서도 실험적 확인이 필요하다. 예로, 기장테두 리진딧물(R.padi)에 Cry1F 내독소를 포함한 $\mathrm{Bt}$ 옥수수를 제공 한 경우 상당량의 내독소가 진딧물 체내에 축적될 수 있음이 보
고되었다(Kim et al., 2012b). 본 연구에서는 진딧물 체내의 Bt 내독소의 양을 정량 하지 않았으나, Burgio 등 $(2007,2011)$ 은 $\mathrm{Cry} 1 \mathrm{Ac}$ 내독소를 포함한 Bt 유채를 제공하였을 때 복숭아혹진 딧물 체내에서 미량의 내독소를 발견하였음을 보고하였다.

본 연구 결과, $\mathrm{Cry} 1 \mathrm{Ac1}$ 내독소를 포함한 $\mathrm{Bt}$ 양배추가 비표 적곤충인 복숭아혹진딧물의 기주식물 선택행동 및 성장에 뚜 렷한 영향을 미치지 않았다. 앞으로의 연구에서는 본 연구의 결 과를 기반으로 양배추를 섭식하는 것이 확인된 다른 진딧물 종 을 연구에 포함시키는 것과 동시에 각 진딧물 체내에 축적되는 내독소의 양을 정량하고, 그 다음단계로 진딧물을 포식하는 포 식자에도 $\mathrm{Bt}$ 양배추가 영향을 미치는지 알아볼 필요가 있다.

\section{사 사}

본 연구는 농림축산식품부 수출전략기술개발사업의 연구비 지원에 의해 수행되었습니다. 복숭아혹진딧물을 분양해 주신 농촌진흥청 국립원예특작과학원에 감사의 말씀을 드립니다.

\section{Literature Cited}

Burgio, G., Lanzoni, A., Accinelli, G., Dinelli, G., Bonetti, A., Marotti, I., Ramilli, F., 2007. Evaluation of Bt-toxin uptake by the non-target herbivore, Myzus persicae (Hemiptera: Aphididae), feeding on transgenic oilseed rape. Bull. Entomol. Res. 97, 211215.

Burgio, G., Dinelli, G., Marotti, I., Zurla, M., Bosi, S., Lanzoni, A., 2011. Bt-toxin uptake by the non-target herbivore, Myzus persicae (Hemiptera: Aphididae), feeding on transgenic oilseed rape in laboratory conditions. Bull. Entomol. Res. 101, 241-247.

Digilio, M.C., Sasso, R., Di Leo, M.G., Iodice, L., Monti, M.M., Santeramo, R., Arpaia, S., Guerrieri, E., 2012. Interactions between $B t$-expressing tomato and non-target insects: the aphid Macrosiphum euphorbiae and its natural enemies. J. Plant Interact. 7, 71-77.

Dutton, A., Klein, H., Romeis, J., Bigler, F., 2002. Uptake of Bt-toxin by herbivores feeding on transgenic maize and consequences for the predator Chrysoperla carnea. Ecol. Entomol. 27, 441-447.

Fernandes, F.S., Ramalho, F.S., Nascimento, J.L., Malaquias, J.B., Nascimento, A.R.B., Silva, C.A.D., Zanuncio, J.C., 2012. Within-plant distribution of cotton aphids, Aphis gossypii Glover (Hemiptera: Aphididae), in Bt and non-Bt cotton fields. Bull. Entomol. Res. 102, 79-87.

Hilbeck, A., Meier, M., Römbke, J., Jänsch, S., Teichmann, H., Tappeser, B., 2011. Environmental risk assessment of genetically modified plants - concepts and controversies. Environ. Sci. Eur. 
23, 13.

Kim, Y.H., Kang, J.S., Kim, J.I., Kwon, M., Lee, S., Cho, H.S., Lee, S.H., 2008a. Effects of Bt transgenic Chinese cabbage on the herbivore Mamestra brassicae (Lepidoptera: Noctuidae) and its parasitoid Microplitis mediator (Hymenoptera: Braconidae). J. Econ. Entomol. 101, 1134-1139.

Kim, Y.H., Kim, H., Lee, S., Lee, S.H., 2008b. Effects of Bt transgenic Chinese cabbage pollen expressing Bacillus thuringiensis Cry1Ac toxin on the non-target insect Bombyx mori (Lepidoptera: Bombyxidae) larvae. J. Asia Pacific Entomol. 11, 107-110.

Kim, Y.H., Hwang, C.E., Kim, T.-S., Lee, S.H., 2012a. Risk assessment system establishment for evaluating the potential impacts of imported Bacillus thuringiensis maize on a non-target insect, Tenebrio molitor. J. Asia Pacific Entomol. 15, 225-229.

Kim, Y.H., Hwang, C.E., Kim, T.-S., Lee, J.-H., Lee, S.H., $2012 b$. Assessment of potential impacts due to unintentionally released Bt maize plants on non-target aphid Rhopalosiphum padi (Hemiptera: Aphididae). J. Asia Pacific Entomol. 15, 443-446.

Kumar, S., Chandra, A., Pandey, K.C., 2008. Bacillus thuringiensis (Bt) transgenic crop: An environment friendly insect-pest management strategy. J. Environ. Biol. 29, 641-653.

Kuiper, H.A., Kleter, G.A., Noteborn, H.P.J.M., Kok, E.J., 2001. Assessment of the food safety issues related to genetically modified foods. Plant J. 27, 503-528.

Lawo, N.C., Wäckers, F.L., Romeis, J., 2009. Indian Bt cotton varieties do not affect the performance of cotton aphids. PLoS ONE 4, e4804.

Lee, S.Y., 2012. Methodology development for Bt rice (Cry1Ac) effect assessment on non-target arthropods. $\mathrm{PhD}$ thesis. Seoul National University.

Liu, X.D., Zhai, B.P., Zhang, X.X., Zong, J.M., 2005. Impact of transgenic cotton plants on a non-target pest, Aphis gossypii Glover. Ecol. Entomol. 30, 307-315.

Lozzia, G.C., Furlanis, C., Manachini, B. Rigamonti, I.E., 1998. Effects of Bt corn on Rhopalosiphum padi L. (Rhynchota: Aphididae) and on its predator Chrysoperla carnea Stephen (Neuroptera: Chrysopidae). Boll. Zool. Agr. Bachic. 30, 153-164.

Lumbierres, B., Albajes, R., Pons, X., 2004. Transgenic Bt maize and Rhopalosiphum padi (Hom., Aphididae) performance. Ecol. Entomol. 29, 309-317.

Oh, S.-D., Lee, D.-Y., Sohn, S.-I., Lee., K.-J., Ryu, T.-H., Lee, J.-Y., Park, B.-S., Kweon, S.-J., Suh, S.-C., Park, J.-S., 2011 a. Risk assessment and evaluation of Bt-transgenic rice: responses of Misgurnus anguillicaudatus and Cyprinus carpio fed on Bt-transgenic rice variety. Korean J. Intl. Agri., 23, 570-577.

Oh, S.-D., Shin, H.C., Sohn, S.-I., Lee, K., Kim, H.-J., Ryu, T.-H.,
Lee, J.-Y., Park, B.S., Kweon, S.J., Suh, S.-C., Park, J.-S., 2011 b. Evaluation and assessment of biosafety for Bacillus thuringiensis (Bt)-transgenic rice: responses of Daphnia magna fed on Bt-transgenic rice variety. J. Appl. Biol. Chem. 54, 296-302.

Park, K.S., 2011. Development of biopesticide and role of Bacillus spp. KIC News 14, 1-11.

Pons, X., Lumbierres, B., López, C., Albajes, R., 2005. Abundance of non-target pests in transgenic Bt-maize: a farm scale study. Eur. J. Entomol. 102, 73-79.

Powell, G., Tosh, C.R., Hardie, J., 2006. Host plant selection by aphids: behavioral, evolutionary, and applied perspectives. Annu. Rev. Entomol. 51, 309-330.

Ramirez-Romero, R., Desneux, N., Chaufaux, J., Kaiser, L., 2008. Bt-maize effects on biological parameters of the non-target aphid Sitobion avenae (Homoptera: Aphididae) and Cry1Ab toxin detection. Pest. Biochem. Physiol. 91, 110-115.

Raps, A., Kehr, J., Gugerli, P., Moar, W.J., Bigler, F., Hilbeck, A., 2001. Immunological analysis of phloem sap of Bacillus thuringiensis corn and of the nontarget herbivore Rhopalosiphum padi (Homoptera: Aphididae) for the presence of Cry1Ab. Mol. Ecol. 10, 525-533.

R Development Core Team, 2012. R: A language and environment for statistical computing. R Foundation for Statistical Computing, Vienna, Austria, ISBN 3-900051-07-0, http://www.r-project.org/. Accessed 22 October 2013.

Romeis, J., Meissle, M., 2011. Non-target risk assessment of Bt crops- Cry protein uptake by aphids. J. Appl. Entomol. 135, 1-6.

Romeis, J., Meissle, M., Bigler, F., 2006. Transgenic crops expressing Bacillus thuringiensis toxins and biological control. Nat. Biotechnol. 24, 63-71

Sohn, S.-I., Ahn, B.-O., Chi, H.-Y., Cho, B.-K., Cho, M.-S., Shin, K.S., 2012. Assessment of microbial community in paddy soils cultivated with $B t$ and Nakdong rice. Korean J. Soil Sci. Fert. 45, 829-835.

$\mathrm{Wu}, \mathrm{K}$., Guo, Y., 2003. Influences of Bacillus thuringiensis Berliner cotton planting on population dynamics of the cotton aphid, Aphis gossypii Glover, in northern China. Environ. Entomol. 32, 312-318.

Wyatt, I.J., White, P.F., 1977. Simple estimation of intrinsic increase rates for aphids and tetranychid mites. J. Appl. Ecol. 14, 757-766.

Zhang, G.-F., Wan, F.-H., Murphy, S.T., Guo, J.-Y., Liu, W.-X., 2008. Reproductive biology of two nontarget insect species, Aphis gossypii (Homoptera: Aphididae) and Orius sauteri (Hemiptera: Anthocoridae), on Bt and non-Bt cotton cultivars. Environ. Entomol. 37, 1035-1042. 